\title{
The Effectiveness of Augmentative and Alternative Communication Application Implementation in Improving Student with Autism Verbal Communication
}

\author{
Nurul Aina Nazri, Aliza Alias \\ Universiti Kebangsaan Malaysia, Malaysia \\ Email: a.nazri1990@gmail.com
}

\begin{abstract}
Augmentative and Alternative Communication is widely used in the educational context as a learning aid for improving verbal communication among students. The aims of this research are to study the effectiveness of Augmentative and Alternative Communication implementation in improving students with autism verbal communication. This research was conducted at one of the primary school in Machang, Kelantan. 2 students with autism participate in this study as a respondent and divided into treatment group and controlled group. Pre and post-tests were conducted to collect and analyze data. Finding in this research shows there was a significant difference between the pre and post-test score in the treatment group when Augmentative and Alternative Communication application was implemented in the intervention.
\end{abstract}

Keywords: Augmentative and Alternative Communication; verbal communication; students with autism

\section{INTRODUCTION}

Autism is a complex neuro disorder that leads to a situation where an individual experiences difficulty in social skills, repetitive behaviors, verbal and nonverbal communication problems and has unique traits and distinctions from other individuals (American Psychiatric Association, 2013). In 2016, The Centers for Disease Control and Prevention released a report stating that the individual ratio of autism increased by 2 times that of 1 in every 68 births in the United States compared to 1 in every 125 births in 2014. Autism children's symptoms can be detected as early as 2 to 3 years old. In certain cases, autism children's can be identified as early as 18 months of age.

In general, autism children do not have the desire to make a request or share their experiences with others. According to Pickles, Risi, \& Lord (2004), 20-50\% of autism children failed to develop speech directly. Therefore, effective early intervention is vital for autism children to promote the development of verbal communication, self-management and social skills, in turn, to assist in their recovery process. Thus, the use of Augmentative and Alternative Communication applications is always recommended to meet their communication needs. Augmentative and Alternative Communication (AAC) is an umbrella term that represents all forms of communication used to express opinions, needs, desires, and ideas. Augmentative and Alternative Communication is also one of the forms of communication that includes medical and social models because Augmentative and Alternative Communication offers contextual support for individual linguistic deficits. (Lord et al., 2004; Robertson, 2009).
Verbal communication is a very important communication medium in everyday life. Through verbal communication, individuals can express their feelings, give their views and express ideas. However, autism children face difficulties in communicating verbally and understanding the communication itself. This is because the ability to communicate with autistic children is varied from one to another. Some may communicate fluently and some may not able to communicate at all. One of the features of autism is the interruption of verbal communication and social interaction that leads to repetitive behavior and distinctive interests (Haynes, Pindzola, \& Emerick, 2008). At least $30 \%$ of children with autism have minimal verbal communication skills (Norrelgen et al., 2015; Anderson et al., 2007). In oral verbalization, autism children only use certain words, short and steady without the proper accompaniment of full sentences and correct grammar. (Zhang, 2016).

Verbal communication and literacy are an important topic discussed in early childhood education (Makin et al., 2007; Scarborough et al., 2009). Children need to master various skills in verbal communication such as vocabulary and correct grammar (pragmatic) usage. The flexibility of children in using verbal language in different contexts is key to them being fluent in everyday communication, Kress (2012). Through communication, children can think, share opinions, gain new knowledge and understand the environment more easily (Halliday, 1975; Halliday \& Hasan, 1989).

Communication and social disabilities are the two main features of autism children (Hill \& Frith, 2003; Rapin \& Dunn, 2003; Landa, 2007; Saracho, 2014). 
The inability to communicate among the autism children in question is speech delays, no response when their names are called, and the orientation of the weak sound and stops chatting at a younger age than typical children (Lord et al., 1996; Tager-Flusberg \& Kasari, 2013; Whitehouse \& Bishop, 2008). In this regard, autism children have problems with verbal communication and thus affect the teaching and facilitating sessions held at the school.

Augmentative and Alternative Communication systems do not use only communication methods but include all communication methods that do not rely on verbal and written language. Augmentative and Alternative Communication systems are widely used in pictures, drawings, and signals as symbols. It can be produced using stationery like pencils and paper or through technology such as computers, tablets, and mp3 devices. Through this medium, children are more likely to show others what they want to say.

According to Light \& Drager (2007), at least $14-20 \%$ of autism children communicate using the Augmentative and Alternative Communication system. Based on the latest study by ThiemannBourque et al. (2016) that examine the effectiveness of peer intervention using the Picture Exchange Communication System (PECS) which is one of the low-tech Augmentative and Alternative Communication systems of spontaneous communication and autism children engagement. Through PECS, autism children are trained to engage in some active social skills. Their findings suggest that there is a change in the therapeutic level of communication and the involvement of autism children in social interactions.

At school, teachers from the special education integration programme have used various teaching strategies and approaches to address verbal communication problems of autistic children but are ineffective. Among them is through collaborative learning, simulation, and discussion. Learning aids are also used to attract children with autism to encourage them to communicate with other children but the results remain the same. In this sequence, researchers have made scientific readings on how to overcome the problem of verbal communication of autistic children.

Based on the Autism Speaks website, which is an advocate and scientific organization dedicated to individuals with autism, at least 648 applications have been listed for the convenience of individuals with autism. Augmentative and Alternative Communication applications are generally used to help students to understand a learning context more easily. Augmentative and Alternative Communication applications can be accessed through gadgets such as tablets, smartphones, and even computers.

Lately, children are more likely to use gadgets such as smartphones and tablets to access some knowledge. These low-cost gadgets are established with their mobility, accessibility, portable and internet access making this gadgets ultimate technology choices to use in the classroom (Neely et al., 2013; O'Malley et al., 2013; Stockall \& Dennis, 2004). Specialized children who take part in special integration education programs also benefit from the implementation of augmentative and alternative communication applications in the classroom. Children with autism, especially the one with verbal communication difficulty also gain advantages with the implementation of Augmentative and Alternative Communication applications in the classroom (Neely et al., 2013).

The purpose of this study was to evaluate the effectiveness of Augmentative and Alternative Communication application in improving autistic student verbal communication. The objectives of the study are: (1) to evaluate the effectiveness of Augmentative and Alternative Communication applications in enhancing autism student verbal communication before and after intervention session; (2) to identify the level of increased verbal communication through the use of Augmentative and Alternative Communication applications between treatment groups and control groups.

\section{METHOD}

The research design used in this study is the action research design. Data were collected using quantitative method through pre and post-test. This study was conducted at one of the primary school in Machang District of Kelantan. Theory of Mind (ToM) by James Mark Baldwin (1861-1934) was used in this study since it is closely related to children with autism. Theory of Mind can be used to refer to autism individuals who do not understand the individual needs around them and are also unique to individuals with autism (Saracho, 2014). Two autism students from this primary school were selected as a research sample through a purposive sampling. Both samples are 11 years old and only able to communicate verbally at minimum levels.

According to Piaw (2014), one of the features of good instruments is to be-be appropriate to the respondent by having a systematic format and arrangement. In this study, the instrument used was pre and post-test. The study samples were first divided into two groups namely treatment groups and control groups. Both treatment and control groups undergo pre-test to measure existing verbal communication levels before the intervention session is conducted. Intervention session for this study conducted for 10 weeks. The intervention session conducted on both groups is twice a week, on Sundays and Thursdays. Each intervention session lasts for 20 minutes and runs on life management subject. 
Table 1. Comparison of verbal communication achievement levels in pre-test and post-test

\begin{tabular}{lccc}
\hline Groups & Respondent & $\begin{array}{c}\text { Pre-Test } \\
\text { Score }\end{array}$ & $\begin{array}{c}\text { Post-Test } \\
\text { Score }\end{array}$ \\
\hline $\begin{array}{l}\text { Treatment } \\
\text { Group }\end{array}$ & $\mathrm{R}_{1}$ & 30 & 55 \\
\hline $\begin{array}{l}\text { Control } \\
\text { Group }\end{array}$ & $\mathrm{R}_{2}$ & 25 & 30 \\
\hline
\end{tabular}

Table 2. Comparison of percentage of achievement between treatment group and control group.

\begin{tabular}{lccccc}
\hline Groups & $\begin{array}{c}\text { Re- } \\
\text { spon- } \\
\text { dent }\end{array}$ & $\begin{array}{c}\text { Pre- } \\
\text { test } \\
\text { scores }\end{array}$ & $\begin{array}{c}\text { Post- } \\
\text { test } \\
\text { scores }\end{array}$ & $\begin{array}{l}\text { Differ- } \\
\text { ences } \\
\text { in pre } \\
\text { test and } \\
\text { post-test } \\
\text { scores }\end{array}$ & $\begin{array}{c}\text { Percent- } \\
\text { age }(\%) \\
\text { increase } \\
\text { in pre- } \\
\text { test and } \\
\text { post-test } \\
\text { scores }\end{array}$ \\
\hline $\begin{array}{l}\text { Treat- } \\
\text { m e n t } \\
\text { Group }\end{array}$ & $\mathrm{R}_{1}$ & 30 & 55 & 25 & 45 \\
\hline $\begin{array}{l}\text { Control } \\
\text { Group }\end{array}$ & $\mathrm{R}_{2}$ & 25 & 30 & 5 & 17 \\
\hline
\end{tabular}

Action research model was used in this research. In the baseline session, respondents were given pre test to evaluate their basic communication.Then, during the intervention session the respondents from the treatment group will be given a tablet and taught verbal communication using Augmentative and Alternative Communication applications. Respondents from the control group will be taught verbal communication using regular teaching. This intervention session were run for 10 weeks. In the $11^{\text {th }}$ week right after the intervention ended, respondents from both groups were given post-test to find out the difference between verbal communication levels of the two groups. In order to obtain the validity of the content, the researcher referred the test item to two superior special education teachers who have vast experiences in the special education field for 20 years.

The data were recorded through pre and post-test scores that conducted on both treatment and control groups. The data were then analyzed using descriptive analysis to measure the percentage improvement of the test scores before and after the intervention using the Augmentative and Alternative Communication application and the regular learning. Data is illustrated in the form of tables to make it easier to understand and interpret by readers.

\section{FINDING AND DISCUSSION}

\section{Findings}

To Evaluate the effectiveness of Augmentative and Alternative Communication applications in enhancing oral verbal communication before and after the intervention session

This section discusses the effectiveness of using Augmentative and Alternative Communication applications in enhancing verbal communication of autism students before and after the intervention session. Table 1 shows the comparison of verbal communication scores through pre and post test.

Based on table 1, the findings showed pre-test score of treatment group (score $=30$ ) while control group ( score $=25$ ). For post-test the treatment group $($ score $=55)$ and the control group ( on pre and post-test scores, the treatment group showed an elevation in verbal communication compared to the control group. This elevation demonstrates the use of Augmentative and Alternative Communication applications to improve verbal communication among autism students as opposed to the use of regular teaching. Therefore, it can be concluded that the use of Augmentative and Alternative Communication applications in learning can improve verbal communication of autism students. The results of this study are consistent with the findings (King et al., 2017 and Ganz et al., 2015) who also stated the use of Augmentative and Alternative Communication applications to enhance verbal communication of autism pupils.

Based on table 2 above, the difference in pre and post-test scores in the $45 \%$ treatment group was higher than the control group of $17 \%$. Respondents 1 showed a high score elevation after using the Augmentative and Alternative Communication application in teaching and facilitating sessions after undergoing post-test. Respondents 2 of the control group using the usual teaching methods also showed a lower elevation of $17 \%$. The high percentage of this treatment group shows the use of Augmentative and Alternative Communication applications is very effective and fun so respondents can improve their own verbal communication.

\section{Discussion}

Autism children are very special children with disabilities. This is because they have unique features that are not exist among typical children. Therefore, they need different approaches, strategies and methods of learning compared with their peers. Based on the study, the use of Augmentative and Alternative Communication applications was seen to enhance autistic children's verbal communication. The elevation 
of verbal communication will help these autism children get place among their peers and they can also express their feelings and wants without using sign language or other body language. Increased scores in post-test on treatment groups and control groups show that Augmentative and Alternative Communication applications have had a great impact on improving verbal communication of autism children.

Due to the efficient use of Augmentative and Alternative Communication applications in enhancing verbal communication of autism pupils, researchers suggested that the Ministry of Education could supply technology equipment such as tablets or smartphones for special integration education classes. This is to make it easier for teachers to use Augmentative and Alternative Communication applications in PdPc in the classroom. Pupils will also be more excited and enjoyable to learn because of their interesting and interactive teaching materials. In addition, researchers also suggested that teachers continue to access the Internet so that they will always have the latest information and information regarding the latest Augmentative and Alternative Communication applications and can help the students learn autism.

This study uses the sample small-sized studies. Further research should continue by using larger sample sizes and wider populations. Findings from this study will be handy for teachers, parents and citizens to use the Augmentative and Alternative Communication application to help increase verbal communication not only for autistic children but also for typical children who may have problems in verbal communication. In general, this research only investigate the effectiveness of implementation of verbal communication in improving student with autism verbal communication. (Schlosser \& Wendt, 2008). Therefore, further research is needed with a focus on the examine the effectiveness of augmentative and alternative communication application to verbal communication skills explicitly.

\section{CONCLUSION}

The implementation of Augmentative and Alternative Communication applications can certainly help in improving the verbal communication of autism students. Through the use of this application, students are more comfortable to cooperate and engage in learning activities with teachers. Additionally, the use of Augmentative and Alternative Communication applications is also seen to help autism students to master verbal communication in total. Therefore, they will gain confidence to communicate using simple words as well as short sentences to express something. Indirectly, they will be able to improve their social skills in the communities and individuals around. This is a positive development for autism children especially in Malaysia.

To strengthen the findings of this study, it is necessary to conduct similar research with larger samples This research only investigate the effectiveness of implementation of verbal communication in improving student with autism verbal communication. Future research should also examine the effectiveness of augmentative and alternative communication application to verbal communication skills.

\section{REFERENCES}

American Psychiatric Association. (2013). Diagnostic and statistical manual of mental disorders (5th ed.). Arlington, VA: American Psychiatric Publishing.

Anderson, D. K., Lord, C., Risi, S., DiLavore, P. S., Shulman, C., Thurm, A., \& Pickles, A. (2007). Patterns of growth in verbal abilities among children with autism spectrum disorder. Journal of consulting and clinical psychology, 75(4), 594604.

Ganz, J. B., Hong, E. R., Goodwyn, F., Kite, E., \& Gilliland, W. (2015). Impact of PECS tablet computer app on receptive identification of pictures given a verbal stimulus. Developmental neurorehabilitation, 18(2), 82-87.

Halliday, M. A., \& Hasan, R. (1989). Language context, and text: Aspects of language in a social semiotic perspective. Deakin, Vic.: Deakin University Press.

Halliday, M. (1975). Explorations in the function of the language. London: Edward

Haynes, W. O., Pindzola, R. H., \& Emerick, L. L. (2008). Diagnosis and evaluation in speech pathology. Boston: Pearson/Allyn and Bacon.

Hill, E. L., \& Frith, U. (2003). Understanding autism: insights from mind and brain. Philosophical Transactions of the Royal Society of London B: Biological Sciences, 358(1430), 281-289.

King, A. M., Brady, K. W., \& Voreis, G. (2017). "It's blessing and a curse": Perspectives on tablet use in children with autism spectrum disorder. Autism \& Developmental Language Impairments, 2, 1-12.

Kress, G. (2012). Perspectives on making meaning: The differential principles and means of adults and children. The SAGE Handbook of Early Childhood Literacy, 55, 329-342.

Landa, R. (2007). Early communication development and intervention for children with autism. Mental retardation and developmental disabilities research reviews, 13(1), 16-25. 
Light, J., \& Drager, K. (2007). Augmentative And Alternative Communication technologies for young children with complex communication needs: State of the science and future research directions. Augmentative and alternative communication, 23(3), 204-216.

Lord, C., Pickles, A., Dilavore, P. C., \& Shulman, C. (1996). Longitudinal studies of young children referred for possible autism. In biannual meetings of the International Society for Research in Child and Adolescent Psychopathology.

Makin, L., Jones-Diaz, C., \& McLachlan, C. (Eds.). (2007). Literacies in childhood: Changing views, challenging practice. Elsevier Australia.

Neely, L., Rispoli, M., Camargo, S., Davis, H., \& Boles, M. (2013). The effect of instructional use of an $\mathrm{iPad} \AA$ on challenging behavior and academic engagement for two students with autism. Research in Autism Spectrum Disorders, 7(4), 509-516.

Norrelgen, F., Fernell, E., Eriksson, M., Hedvall, Å., Persson, C., Sjölin, M., \& Kjellmer, L. (2015). Children with autism spectrum disorders who do not develop phrase speech in the preschool years. Autism, 19(8), 934-943.

O'malley, P., Lewis, M. E. B., \& Donehower, C. (2013). Using tablet computers as instructional tools to increase task completion by students with autism. American Educational Research Association, $1-27$.

Piaw, C. Y. (2014). Relationship between thinking styles and ability to pay attention of Malaysian male and female student teachers. Procedia-Social and Behavioral Sciences, 116, 4839-4843.

Pickles, A., Risi, S., \& Lord, C. (2004). Trajectory of language development in autistic spectrum disorders. In Developmental language disorders (pp. 18-41). Psychology Press.

Rapin, I., \& Dunn, M. (2003). Update on the language disorders of individuals on the autistic spectrum. Brain and development, 25(3), 166-172.
Robertson, S. M. (2009). Neurodiversity, quality of life, and autistic adults: Shifting research and professional focuses onto real-life challenges. Disability Studies Quarterly, 30(1).

Saracho, O. N. (2014). Theory of mind: understanding young children's pretense and mental states. Early child development and care, 184(8), 1281-1294.

Scarborough, H. S., Neuman, S., \& Dickinson, D. (2009). Connecting early language and literacy to later reading (dis) abilities: Evidence, theory, and practice. Approaching difficulties in literacy development: Assessment, pedagogy and programmes, 23-38.

Schlosser, R. W., \& Wendt, O. (2008). Effects of augmentative and alternative communication intervention on speech production in children with autism: A systematic review. American Journal of Speech-Language Pathology, 17(3), 212-230.

Stockall, N., \& Dennis, L. R. (2014). Using pivotal response training and technology to engage preschoolers with autism in conversations. Intervention in School and Clinic, 49(4), 195-202.

Tager-Flusberg, H., \& Kasari, C. (2013). Minimally verbal school-aged children with autism spectrum disorder: the neglected end of the spectrum. Autism Research, 6(6), 468-478.

Thiemann-Bourque, K., Brady, N., McGuff, S., Stump, K., \& Naylor, A. (2016). Picture exchange communication system and pals: A peer-mediated augmentative and alternative communication intervention for minimally verbal preschoolers with autism. Journal of Speech, Language, and Hearing Research, 59(5), 1133-1145.

Whitehouse, A. J., \& Bishop, D. V. (2008). Cerebral dominance for language function in adults with specific language impairment or autism. Brain, 131(12), 3193-3200.

Zhang, Y. (2016). Zhang_Yu_2016_MDes_INCD_A Culturally Inclusive AAC App for Children with Autism in China. A Culturally Inclusive AAC App for Children with Autism in China. 